\title{
Changing Attitude of Women towards Infertility and Motherhood
}

\author{
Adhikari Harasankar ${ }^{*}$ \\ ${ }_{1}$ Social Worker and Independent Scholar, Monihar Co-operative Housing Society, Flat No.-7/2, 1050/2, Survey Park, Kolkata- \\ 700075, West Bengal, India
}

KEYWORDS

Infertility

Motherhood

Marital relation

Career life

Living pattern

\begin{abstract}
The present study was conducted among the employed women $(\mathrm{N}=50)$ at their reproductive age (25-35 years) of urban Kolkata to elucidate their changing attitudes towards infertility and motherhood. We found that the women were very much attentive to their personal happiness and career. They did not believe to perform their traditional female roles because in their opinion it was a restriction of achieving their equity and justice in our patriarchal society. They were engrossed into most modern urban mode of life. They did not prefer to enter into their marital relation because it would be a threat to cherish their happiness. Even in their opinion infertility would not be a stigma in women's lives because it would be an obstacle for their freedom and self progress in their working life. But they would prefer to enjoy the taste of motherhood otherwise rather than biologically. Thus reproductive rights of women were violated through their overall behaviour.
\end{abstract}

\section{Introduction}

The concept of the female in Hindu Society represents a duality - the woman is fertile, benevolent, the bestower, and then she is aggressive and malevolent- the destroyer. The female symbolizes in Hindu society a combination of 'shakti' (energy/power) and 'prakriti' (nature) (Wadley 1998). There are three stages in her lifecycle - a daughter to the parents, wife

\footnotetext{
* Contact address: jaoya123@yahoo.co.in (A. Harasankar)
} 
to her husband and a mother to her child. They are trained to learn the mandatory skills of housekeeping, cooking and child care to shape her future as a good daughter, good wife and good mother and so forth (Wadley 1998).

In Indian society the motherhood is revered as a moral, religious and even artistic deal. It brings family acceptance and emotional well-being and changes dramatically once she becomes pregnant. Pregnancy offers a resolution to insecurity, doubt and the shame of infertility. Pregnancy marks the beginning of a woman's adult identity (Wadley 1998). Motherhood is not only the personal fulfilment of womanhood and the biological achievement of a lifelong promise, but it confirms her status in renewing her race. So, infertility is important not only in context of its physical entity but as a social milieu too (Dyer et al. 2002). It can have serious implications for the psychological, physical, economic and social well-being for both spouses, but more so for women, as motherhood is seen as a supreme achievement for a woman and demonstrates her physical and psychological adequacy. It is generally in underdeveloped and developing countries that this is seen as linked to an act of God and punishment for sins of the past. However, prolonged use of contraceptives, distinct dietary habits, and the result of witchcraft are also seen as causing childlessness. While people in developed countries view infertility as caused by biological and other related factors (Bharadwaj 2000; Boivin et al. 2007), it has been revealed from various studies that severe emotional harassment is experienced by a large number of women who are infertile in their marital homes, in the form of ostracism from family celebrations, taunting and stigmatization, negative attitudes as well as domestic violence, and the withholding of food and health care (Dyer et al. 2005). In Bengali Culture it is stigmatized as 'banja' (in Bengali dialect meaning infertile).

Infertility among working women is increasing. Women who are goaloriented and independent don't want to get married early in life and have children. Birth control strategies now enables sexual fulfilment before marriage and protects women from unwanted pregnancies. Moreover, long 
hours of work and stress often lead to infertility (Boivin et al. 2007) because it often results in hypertension, high blood pressure and heart disease, etc. Further, doctors believe that 'infertility causes stress: stress does not cause infertility' (Akker 2005). Secondly, the factors that lead to increasing infertility amongst women is that most of them do not want to get married before the age of thirty and even if they have to get married in their twenties, they do not usually plan to have an early pregnancy. Doctors say that women's infertility rate is 10 to 15 per cent when they are in their 20 s and goes up to 25 per cent in their 30s. In women, hectic lifestyles and job stress contribute to conception problems (Abbey, Andrews, and Halman 1992). A very common cause is polycystic ovary disease (PCOD), a condition characterized by excess production of hormones and lack of ovulation. There are others such as genital tuberculosis (a chief factor in rural India), fallopian tube defects, endometriosis, a condition characterized by abnormal growth in the woman's reproductive system, multiple partners and STDs that might permanently damage the woman's reproductive system. Life style choices such as smoking, tobacco consumption, drinking, obesity and hormonal imbalances such as polycystic ovaries and hypothyroidism are also responsible contributing factors (Boivin et al. 2007).

\section{Methods}

\section{Aim of the study}

The objective of the study was to explore the changing attitudes of women towards infertility and motherhood in a context where the feminist movement aims to achieve equal status in a patriarchal society.

\section{Participants}

For the purpose of the study 50 women at their reproductive age (25-35 years) were randomly selected. Their educational backgrounds, employment patterns and marital status were all considered. All of them were from 
Bengali cultural backgrounds and were living in Kolkata Metro City and its suburbs.

\section{Procedure}

The researcher met respondents at beauty salons, schools, colleges and shopping centres during their leisure/recess time. Firstly, the interviewer interacted with them informally and he shared the aims of his discussion. The respondents happily participated and they expressed their views on specific aspects of their equality and justice.

\section{Research tools}

A structured interview schedule was used for the collection of data in which the issue of infertility and motherhood were the primary subject. Marriage, marital relations, family life, and ideas about parenting and parental roles and other related aspects were the points of discussion for the study.

\section{Result \& Discussion}

\section{Demographic description of women participating in the study}

According to Table 1, the women in the sample are mostly employed in the private sector (82\%) and half of them are graduates. Of these, $30 \%$ belong to

Table 1. Employment status of women in respect of their age and educational background

\begin{tabular}{|c|c|c|c|c|c|}
\hline \multirow{3}{*}{ Educational background } & \multicolumn{4}{|c|}{ Employment sector } & \multirow{3}{*}{ Total } \\
\hline & \multicolumn{2}{|c|}{ Public sectors } & \multicolumn{2}{|c|}{ Private sectors } & \\
\hline & $25-30$ years & $30-35$ years & 25-30 years & $\begin{array}{l}30-35 \\
\text { years }\end{array}$ & \\
\hline Higher secondary $(10+2)$ & - & - & $2(4 \%)$ & $1(2 \%)$ & $3(6 \%)$ \\
\hline Graduate $(10+2+3)$ & $1(2 \%)$ & $4(8 \%)$ & $15(30 \%)$ & $10(20 \%)$ & $30(60 \%)$ \\
\hline Post graduate $(10+2+3+2)$ & - & $2(4 \%)$ & $4(8 \%)$ & $3(6 \%)$ & $9(18 \%)$ \\
\hline Professional degree/ certificate & - & $2(4 \%)$ & $6(12 \%)$ & - & $8(16 \%)$ \\
\hline Total & $1(2 \%)$ & $8(16 \%)$ & $27(54 \%)$ & $14(28 \%)$ & $50(100 \%)$ \\
\hline
\end{tabular}


the age group 25-30 years, while only $18 \%$ are engaged in the public sector, out of which $16 \%$ are under the age group $30-35$ years and $8 \%$ of these women are graduates.

Table 2 shows that, among the respondents, the majority (46\%) are still single between the age of $30-35$ years $(12 \%)$. Secondly, $54 \%$ of them have been in conjugal relations for $2-8$ years. But $20 \%$ of them were either separated or divorced. $14 \%$ of them were within the age group of 25-30 years. The respondents within $25-30$ years of age were mostly single (22\%).

Table 2. Marital status in respect of age and education

\begin{tabular}{llllllll}
\hline \multirow{2}{*}{$\begin{array}{c}\text { Educational } \\
\text { background }\end{array}$} & \multicolumn{2}{c}{ Unmarried } & \multicolumn{2}{c}{ Marital status } \\
& $25-30$ & $30-35$ & $25-30$ & $30-35$ & $25-30$ & $30-35$ & Total \\
& years & years & years & years & years & years & \\
\hline Higher Secondary & - & - & $1(2 \%)$ & $1(2 \%)$ & $1(2 \%)$ & - & $3(6 \%)$ \\
Graduate & $11(22 \%)$ & $4(8 \%)$ & $2(4 \%)$ & $8(16 \%)$ & $3(6 \%)$ & $2(4 \%)$ & $30(60 \%)$ \\
$\begin{array}{l}\text { Post graduate } \\
\text { Professional }\end{array}$ & $2(4 \%)$ & $2(4 \%)$ & $1(2 \%)$ & $2(4 \%)$ & $1(2 \%)$ & $1(2 \%)$ & $9(18 \%)$ \\
degree/certificate & $4(8 \%)$ & - & - & $2(4 \%)$ & $2(4 \%)$ & - & $8(16 \%)$ \\
\hline Total & $17(34 \%)$ & $6(12 \%)$ & $4(8 \%)$ & $13(26 \%)$ & $7(14 \%)$ & $3(6 \%)$ & $50(100 \%)$ \\
\hline
\end{tabular}

\section{Living pattern, life style and habits}

Table 3 (a) shows that $30 \%$ of the respondents within the age of $25-30$ years were living in their family either with their parents or they were settled with their in-laws family, but $22 \%$ of them were living as a paying guest and $20 \%$ were in other accommodation. They declared that they did not prefer to live with the family before marriage because their privacy and secrecy were violated by interference from the seniors in their family. In their opinion it was due to gender discrimination, while the boys were not monitored in their family. 
Table 3(a). Living pattern

\begin{tabular}{llllll}
\hline Age groups & $\begin{array}{c}\text { In family with parents } \\
\text { or in laws family or } \\
\text { both spouses }\end{array}$ & $\begin{array}{c}\text { Living pattern } \\
\text { In relatives } \\
\text { family }\end{array}$ & $\begin{array}{c}\text { Paying } \\
\text { guest }\end{array}$ & Other & Total \\
\hline $25-30$ years & $15(30 \%)$ & - & $7(14 \%)$ & $6(12 \%)$ & $28(56 \%)$ \\
$30-35$ years & $10(20 \%)$ & $4(8 \%)$ & $4(8 \%)$ & $4(8 \%)$ & $22(44 \%)$ \\
\hline Total & $25(50 \%)$ & $4(8 \%)$ & $11(22 \%)$ & $10(20 \%)$ & $50(100 \%)$ \\
\hline
\end{tabular}

Table 3(b) describes some habits adopted in their daily life. They were accustomed to different modes of amusement and entertainments. Among them, $44 \%$ consumed alcohol/tobacco out of which $32 \%$ were $25-30$ years of age. An equal percentage of these women also visited the discotheque. Only $12 \%$ usually used their leisure for reading, writing and travelling, etc.

Table 3(b). Habits/entertainment in life

\begin{tabular}{lcccc}
\hline \multirow{2}{*}{ Age group } & \multicolumn{3}{c}{ Habits/mode of entertainment } & \multirow{2}{*}{ Total } \\
\cline { 2 - 4 } & Tobacco & Party/discotheque & Reading/writing, etc & \\
\hline 25-30 years & $16(32 \%)$ & $10(20 \%)$ & $2(4 \%)$ & $28(56 \%)$ \\
$30-35$ years & $6(12 \%)$ & $12(24 \%)$ & $4(8 \%)$ & $22(44 \%)$ \\
\hline Total & $22(44 \%)$ & $22(44 \%)$ & $6(12 \%)$ & $50(100 \%)$ \\
\hline
\end{tabular}

\section{Relationship with male partners as a husband or partner (reasons behind being unmarried, divorced or separated)}

The observations of the participants reflect attitudes towards personal freedom and the domination of males in a patriarchal society. They commonly viewed the same sex older generation as having to face a life that was little more than acting as a slave as they performed their duties as family care taker. The relationship with their male partner in their view, however, was one of security and mutual understanding for enjoyment. 
They did not believe that it should always be sanctified by marriage. The romantic or dating relationship with a male partner was to them as a trait of happiness. In that relationship there was neither risk nor burden. On the other hand the male as conjugal partner would generally bring restriction to their personal life. The in-laws family and their male partner would play a role of watchdog to monitor their faithfulness. This was the conflict of interest which had brought their marital separation or divorce after a steady relation of more than five years before marriage. Surprisingly most of them preferred to choose their marital partner through a romantic relationship. A second reason for their broken spousal relation was their inability to bear children as a result of their infertility problems. To them infertility was not a stigma. To testify to their motherhood they could always adopt a baby.

For the single/unmarried women in this study, corporate life meant that motherhood would be a hindrance to upward progression in their career. So, in their words: 'go steady to establish in job market'. Nor could they be sure that romantic relations would result in marital relations.

\section{Status of fertility among married women}

Among the married women $(\mathrm{N}=28)$ of this study, 25\% had children and a majority of them $(17.8 \%)$ had a single child (Table 4 ). The remaining $75 \%$ had no children because of biological issues (28.5\%), the use of contraception $(21.4 \%)$ and abortion (25\%). We found that $17.8 \%$ of these women within the age group of 30-35 years had biological problems and the rate of abortion was $14.2 \%$. The abortion rate was $10.7 \%$ in case of the age group $25-30$ years. While they saw some of the risks involved with this, they did not feel this was an issue because pregnancy would impede their personal enjoyment in life and adversely affect their physical attractiveness. 


\section{Motherhood and child care}

In this study the respondents were economically self-sufficient and enmeshed within the consumer world. They mostly preferred freedom in their life and sought gender equity. They did not believe in the traditional role of women. To them personal freedom in every sphere of life would improve their self-identity. In their lives, earning and enjoyment were the main components. Child bearing and child-rearing would impede their personal progress in their career resulting in them entering the same cycle as their older generation.

Table 4. Fertility status of married women according to their age

\begin{tabular}{|c|c|c|c|c|c|c|}
\hline \multirow{3}{*}{ Age groups } & \multicolumn{5}{|c|}{ Fertility status } & \multirow{3}{*}{ Total } \\
\hline & \multicolumn{2}{|c|}{ Having child } & \multicolumn{3}{|c|}{ Not yet } & \\
\hline & Single & $\begin{array}{c}\text { Two \& } \\
\text { more }\end{array}$ & $\begin{array}{c}\text { Biological } \\
\text { problem }\end{array}$ & $\begin{array}{c}\text { Use of } \\
\text { contraception }\end{array}$ & Aborted & \\
\hline $25-30$ years & $2(7.1 \%)$ & $2(7.1 \%)$ & $3(10.7 \%)$ & $4(14.2 \%)$ & $3(10.7 \%)$ & $14(50 \%)$ \\
\hline $30-35$ years & $3(10.7 \%)$ & - & $5(17.8 \%)$ & $2(7.1 \%)$ & $4(14.2 \%)$ & $14(50 \%)$ \\
\hline Total & $5(17.8 \%)$ & $2(7.1 \%)$ & $8(28.5 \%)$ & $6(21.4 \%)$ & $7(25 \%)$ & $28(100 \%)$ \\
\hline
\end{tabular}

\section{Conclusion}

Global society has brought changes in everyday life for people through education and the opening of multifarious employment avenues. Girls' education has gradually increased in importance in Indian society. It is evident that girls are now participating and attaining in their education and where they see themselves in a new corporate world (Radhakrishnan 2012) in which they are no longer a liability to their parents, no longer under male domination, but are seen as assets to their family. The feminism and the feminist movement have facilitated education and employment among women and have brought many positive changes in the empowerment of women (Wadley 1998). For the participants in this study this is the step to equity and justice and away from the male politics of motherhood (Rich 
1986). Participants no longer accept childbearing as a female duty, preferring adoption or other methods by which they would be able to enjoy motherhood.

\section{References:}

Abbey, Antonia, Frank M. Andrews and L. Jill Halman. 1992. "Infertility and Subjective Well-Being: The mediating roles of self-esteem, internal control, and interpersonal conflict". Journal of Marriage and Family 54 (2): 408-417.

van den Akker, Olga B.A. 2005. "Coping, quality of life and psychosocial symptoms in three groups of subfertile women". Patient Education and Counselling 57 (2): 183-189.

Andrews, Frank M., Antonia Abbey and L. Jill Halman. 1991. "Stress from Infertility, Marriage factors, and subjective being of wives and husbands". Journal of Health and Social Behaviour 32 (3): 238-253.

Bharadwaj, Aditya. 2000. "Infertility and Gender: a perspective from India". In Social Science Research on Childlessness in a Global Perspective: proceedings of the conference: 8-11 November 1999, Amsterdam, The Netherlands, edited by Frank van Balen, Trudy Gerrits, and Marcia Claire Inhorn, 65-74. Amsterdam: SCO-Kohnstamm Instituut.

Boivin, Jacky, Laura Bunting, John A. Collins and Karl G. Nygren. 2007. "International estimates of infertility prevalence and treatmentseeking: potential need and demand for infertility medical care". Human Reproduction 22 (10): 2800-2800.

Dyer, Silke J., Naeemah Abrahams, Margaret Hoffman, and Zephne Van der Spuy. 2002. " «Men leave me as I cannot have children»: women's experiences with involuntary childlessness". Human Reproduction 17 (6): 1663-1668.

Dyer, Silke J., Naeemah Abrahams, Nonhlanhla F Mokoena., Carl J. Lombard, and Zephne Van der Spuy. 2005. "Psychological distress among women suffering from couple infertility in South Africa: a quantitative assessment". Human Reproduction 20 (7): 1938-1943.

Radhakrishnan, Smitha. 2012. Appropriately Indian: gender and culture in a new transnational class. New Delhi: Orient Blackswan.

Rich, Adrienne Cecile. 1986. Of Woman Born: Motherhood as Experience and Institution. New York: W W Norton \& Company Incorporated.

Wadley, Susan. 1998. "Women and the Hindu Society". In Women in Indian Society, edited by Rehana Gadhiall, 21-24. New Delhi: Sage Publications. 